\title{
Necessidades Básicas da Transição Paradigmática: O Ciclo Pré-Clínico
}

\section{RESUMO}

O autor discute a estrutura organizacional das c'scolas médicas, bem como a disponibilidade e: a qualificação de meios à lu\% dos objetivos maiores dessas instituiçoes. Conclui que se não falta o discurso do reconhecimento da relevância de ciclo pré-clínico, há erros na operacionalização do ensino. Nias atuais condiçues cle nem concurre para a formaçăo de cientistas e nem propicia sólicóo alicerce para a capacitaçóo profissional adeçuada.

\section{INTRODUÇÃO}

O titulo deste artigo diz. respeito ao periodo pré-clínico da educaçāo médica. De longa data a etapa ensino básico tem sido objeto de análise e crítica; e, nos últimos anos, sujeita a alteraçōes consideráveis em sua organizaçāo e conteúdo.

Esta discussāo ocorre em momento histórico, que corresponde a mudanças em conceitos que orientaram a formaçāo do médico ao longo do século que finda.

O exame do tópico nāo desconsidera condições específicas de tempo e lugar, e nem ignora a diversidade de intérpretes. Por exemplo, no entender de Stokes, ${ }^{26}$ as escolas médicas raramente podem ser consideradas modelos de boa organizaçāo.** A razāo principal, segundo ele, reside na variedade de compromissos a que elas estāo sujeitas.

Dentro deste cenário de multiplicidade de atividades-fins, admitida como uma das razōes da desorganiza-

PALAVRAS-CHAVE:

Educação médica;

Ciências básicas;

Paradigma. 


\section{PARADIGMA}

O paradigma pode ser entendido como uma espécie de matriz. disciplinar, servindo como referencial para um conjunto de conceitos relativos a um mesmo fenômeno. De acordo com o pensamento de Kuhn, ${ }^{14}$ em uma determinada época, o paradigma plasma posições intelectuais e influencia comportamentos, no esforço de resolução de questōes relativas ao conhecimento. A situação permanece em estado de equilíbrio, enrai\%ada, até que algo diferente do normal provoque uma crise. Dessa última situação pode ocorrer uma ruptura com a versāo tradicional, surgindo um novo paradigma. Durante a fase de transiçāo paradigmática convivem, por algum tempo, o velho e o novo paradigma: o velho, em seu esforço por continuar dominante, e o novo em sua luta para ganhar novos adeptos.

\section{PARADIGMA FLEXNERIANO}

A importância dos departamentos de ciências básicas pode ser identificado na discussāo de Flexner " acerca da educação médica. O relatório por ele elaborado, em 1910 para a Carnegie Foundation for the Advancement of Teaching, é fundamental na orientação da educação médica americana: ele instituiu reformas profundas naquele país, induzindo outras tantas em diversas naçōes. ${ }^{*}$

Não será demais falar-se de um paradigma Flexneriano. ${ }^{24} \mathrm{Com}$ base nele a pesquisa foi definitivamente institucionalizada na escola médica, seus laboratórios melhorados, os cursos de ciências reforçados no periodo pré-clínico. Também os cursos da etapa de aplicação e as relações do hospital com a escola médica foram objeto de análise e recomendaçōes. Em resumo, o relatório produzido por Flexner contribuiu para elevar a qualidade do ensino médico, permitindo a construção do (conhecimento do empírico para o científico), da observação para a experimentação.

Também não pode passar despercebido que o relatório aponta uma situação anárquica, com proliferação indiscriminada de escolas médicas."

Sem negar a importância da base científica do desenvolvimento e da tecnologia médica, há que se admitir que as novas necessidades sociais ${ }^{3,9}$ representam um importante componente naquilo que Kuhn ${ }^{14}$ chama de transiçāo paradigmática, instalando-se o conflito em razão da necessidade de preservação versus a vontade de instalação de uma nova ordem conceitual.

\section{EXPANSĀO DO ENSINO SUPERIOR}

A expansão do ensino superior desacompanhada de recursos humanos e físicos, qualificados e adequados, só poderia determinar rebaixamento da qualidade do ensino médico. ${ }^{25}$

Esta expansāo, em tempo muito curto, não se acompanhou de meios adequados que justificassem o conceito de formação profissional fundamentada na medicina "ciência." O que se viu foi o surgimento de escolas isoladas em ambientes impróprios, adaptados, sem recursos mínimos de equipamentos e bibliotecas e, principalmente, sem professores pré-clínicos qualificados. Com a expansão, proliferação das escolas médicas, aqueles objetivos do paradigma citado tornaram-se dificeis de conquistar.

Lopes Pontes ${ }^{18}$ discute com muita clareza o ocorrido e aponta as vantagens da integração da escola médica no campus universitário. Poucas instituiçōes, contudo, puderam contar com essas possibilidades. Manifestamente, diz ele, os cursos foram insuficientes para atender a preparação de professores, adotando critérios alternativos, administrativos, para acesso às categorias docentes.

A má-qualificação do corpo docente e a precariedade de recursos físicos (não sendo excepcionais as situaçōes em que eles são insatisfatórios até mesmo para o ensino de ciências em escolas de segundograu), trouxeram sérias conseqüências para o ciclo pré-clínico.

Pereira ${ }^{20}$ exemplifica: um exame parasitológico das feres serve para demonstração a 100 alunos e uma placa bacteriana passa de mão em māo, para observação atônita de quem não sabe semear um germe, e, muito menos, compreende o sentido do crescimento de uma colônia ou halo em volta do disco de antibiótico.

\section{ESTRUTURA ORGANIZACIONAL}

As instituiçōes de ensino superior, em qualquer lugar, e a qualquer tempo, têm um certo número de características fundamentais, ${ }^{27}$ as quais serão comentadas a seguir com brevidade.

$\Lambda$ primeira característica diz respeito a autoridade do pessoal acadêmico. Nessas instituiçōes muitas decisōes só podem ser tomadas por profissionais especialistas.

Uma segunda característica é o princípio organizacional. As áreas do conhecimento são os "building blocks": alega-se que sem sua institucionalização uma organização de ensino superior nāo poderia

\footnotetext{
"First and Last, American tew'ns have ponduced over four hundred medical schools. The lesching of medicine on these terms ivas, directly, in cash, and indirert, in prestige, a profitable busincss." Flexilct, op. cit. p.4t.
} 
existir. Este princípio conduz à formação de "células especializadas", autônomas, os departamentos, o que concorre para a fragmentação e a pouca consistência do conjunto.

A terceira caracteristica é a difusāo do poder decisćrio, que passa a ser distribuido entre grande número de unidades e atores. A instituição torna-se, como conseqüência, um sistema federativo: departamentos autônomos (ou quase) em busca de seus interesses que podem se sobrepor à autoridade do conjunto. Esta organização reclama o exercício do poder-dever pela autoridade competente - supremacia nas relaçōes de qualquer natureza que a escolha interna reclama.

Concorrendo também para a fragmentação do ensino está a chamada disciplina, com equivoco de interpretação de significado e reflexo na organização do currículo. O conceito de disciplina acadêmica não é claro, inequívoco. Vale remeter à discussão do assunto por Becher. ${ }^{4}$ Também convém referir o exame do conflito de interesses (objetivos institucionais versus os objetivos das disciplinas). Elas, "ilhotas institucionais", vivem em democracia, seja por que são autóctones ou por que foram adotadas para cumprir alguma função exigida na estrutura curricular. Em conjunto, autóctones e desligadas das metas institucionais, em departamentos autônomos, configuram uma estrutura arcaica de baixa eficácia educacional. ${ }^{3}$ É negar que a educação profissional ampla e a formação cultural dos estudantes são a missão básica dessas instituiçōes. ${ }^{6}$

Uma impropriedade na coordenação dos cursos é a superposição dà organização departamental à estrutura curricular.* É essencial entender que o planejamento curricular sobrepōe-se à vontade departamental. Os departamentos persistem assegurando o registro de disciplinas só a eles vinculado, e mantendo a autonomia das decisōes relativas às suas origens. ${ }^{10}$

A raiz dessas distorçōes foi discutida por Rosa, ${ }^{23}$ que concluiu ser necessário desfazer "finalidades" (dentre elas, o uso de poder, até mesmo confundindo-se com estrutura de serviço) das disciplinas de graduação, que não devem ser entendidas senão como formas adequadas de organização da matéria necessária à qualificação do aluno. As disciplinas não podem ser confundidas como estrutura de poder ou liderança. ${ }^{23}$

\section{DICOTOMIA DO ENSINO MÉDICO}

De assunto tão candente muitos têm-se ocupado, e a literatura é

\footnotetext{
- Em contraposição a t'stes conccitos, há estatutus que concedem repnesentaçào na congre gação aos

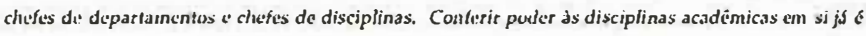
um equfvoco conccitual. As consi'qüèncias práticas esisuaf manifestas, até mosmo pela desigualdado numérica cutre uns ce outnss: esvazia-se od epartamento fndu se jgnora a fraqueza dessa cestrueura te do

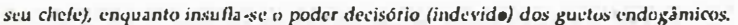

agora volumosa. A maioria deriva da mesma idéia: a separação do ensino, em etapas, pressupondo ser uma delas essencial à boa formação do médico. É preciso admitir-se que o ambiente, no qual ocorre a educação médica, deve ser estimulante sobre o aspecto acadêmico, incluindo a pesquisa, que não pode ser dissociada do ensino.

Durante os primeiros anos do curso é essencial a organização do ensino pré-clínico, de tal modo que sua aplicaçào à Medicina seja sempre óbvia. Esta é a razão para o ensino combinado e integrado das diferentes disciplinas, em associação ilustrativa ao significado da pesquisa na formação do aluno.

Todavia, não só persiste como se acentua a ruptura entre o ideal e o plano da realidade. O idealé o relacionamento da qualidade com os usuários, isto é, o ensino pré-clinico de ciências é essencial à boa formação do médico. A realidade, contudo, é bem diferente. Em nosso meio, há algumas agravantes.

Os padrōes da educação médica, lastreada em sólida formação nas ciências básicas, foram introduzidos tardia e lentamente entre nós. Referidos padrōes só poderiam ser alcançados se a instituição estivesse de posse dos recursos necessários aos conceitos fundamentais. $O$ que não é o caso.

\section{CICLO PRÉ-CLÍNICO}

Au cliscutir à importância do ciclo pré-clénico, Sinclair ${ }^{55}$ enfatiza que os professores deveriam ensinar os fatos e princípios de suas idéias, de tal modo que os alunos passem para o ciclo clínicu com compreensão adequada, metodologia e vocabulário que os beneficiem em seus estudos futuros.**

Mas as disciplinas das áreas básicas - tal como são ministradas e assimiladas - nāo chegam a caracterizar para o alunado que o corpo de matéria abordado constitui embasamento indispensível para a formação profissional diferenciada. Cabe, até mesmo, a interpretação de que o ciclo pré-clínico é vivenciado como etapa formal a ser cumprida por mera exigência curricular.

Do cenário supra referido resulta a formação defeituosa que thes (os alunos) tolhe intensa e precocemente a compreensão dos mecanismos fisiopatológicos das entidades mórbidas com que se deparam e devem tratar. ${ }^{1}$

\footnotetext{
"They had to tedch students different habits of thought to wean them away from the parroting of texts and teachers and to bring them nearer the buginning of independent judgement. Sinclair, op. cit, p. 13. - Inquicrito nualizado entin ingressuntes de cescolas médicas publicas e privadas, no Estado de Sáo Paule, nevela que cerca de $60 \%$ afirman náo ter havido qualquer orientaçio sobne a unganizaşo do cursto. Dades do autor n.jo publicudos.
} 
Estas são consideraçōes gerais, cabendo breve referência a fatores concorrentes e determinantes dessas observaçōes.

\section{O ESTUDANTE}

Por ocasião da admissão à escola médica, o aluno tem, geralmente, 18 a 20 anos de idade. A má qualidade da escolaridade prévia ao ensino superior que tanto aflige educadores e com tanta repercussão, é fator de grande importância.

Idealmente, três requisitos devem ser esperados de um estudante. O primeiro exige-lhe a posse de conhecimentos e hábitos fundamentais. Ser capaz de comunicar-se com outras pessoas, com dominio suficiente de linguagem falada e escrita para compreender instruçōes complicadas e fazer julgamentos claros. ${ }^{15} \mathrm{~A}$ abordagem feita por Hossne $^{12}$ acerca da responsabilidade ética da linguagem é referência obrigatória. O segundo, apreciar o domínio do conhecimento comouma atividade gratificante. $O$ terceiro, aprender a pensar por si mesmo.

O que se constata, quando um novo aluno chega ao curso superior, é uma desconcertante variedade de departamentos e uma diversidade não menos atordoadora de disciplinas. ${ }^{6}$ E não existe nenhuma orientação lógica, nenhum acordo com a escola universitária sobre 0 que ele deveria estudar.* O resultado é a falta de percepção do aluno para identificar a relevância das ciëncias básicas entre si e seu vínculo com a Medicina clínica. ${ }^{5}$

\section{DISCIPLINAS}

As disciplinas do ciclo pré-clínico (a Fisiologia é destacado exemplo) representam a base para a capacidade de distinguir "núcleo de arte empirica" do conteúdo de "ciência na Medicina". Elas são essenciais para o aluno compreender e separar o provável do incerto, de pesar a evidência e chegar à conclusão provisória do que deve ser testado. ${ }^{25}$ Essas aptidōes de análise e síntese são conducentes ao futuro raciocinio lógico de diagnóstico diferencial. As disciplinas básicas incitam o hábito de avaliação crítica do "fato" apresentado para consumo, e induzem no estudante um modo de pensar aplicável aos problemas e dificuldades, preparando-o para o exercício de atividades profissionais.
Considerável parte do ensino pré-clínico é ministrada em aulas expositivas, sendo as práticas estereotipadas com a preocupação de reproduzir experimen tos clássicos. Mas o papel do curso deve ir muito além: cabe-lhe a responsabilidade de encorajar o aluno para uma atitude cientifica, a fazer julgamentos claros e a perceber a importância do assunto para a formação médica.

Não é fácil para a disciplina, como "unidade de ensino", atendera o slogan educacional "cut out the dead wood." Essa dificuldade deriva, em parte, da incapacidade de o professor reconhecer a "dead wood":"21 o resultado é que grande parte desse conhecimento será totalmente despido de valor e de significado na prática médica**.

Curiosamente dificuldades na correção dessas distorçōes têm origem dentro da própria disciplina. ${ }^{2}$ Já não se fala do ideal da integraçāo, mas do ideal da coordenaçāo e da propriedade da matéria e seu modo de apresentação. ${ }^{9}$

\section{INFRA-ESTRUTURA}

O paradigma Flexneriano dá ênfase à institucionalização da pesquisa na escola médica, seus laboratórios melhorados, os cursos de ciências reforçados no ciclo pré-clínico. O que a prática revela entre nós é uma completa negação desses preceitos .

As condiçōes de infra-estrutura são inadequadas à complexidade pretendida e materializada nas ementas das disciplinas. As condiçōes físicas, precárias, estāo muitas vezes inabilitadas até mesmo para o ensino de ciências no segundo grau. Não se fale em falta de modernização de equipamentos: esses, ressalvadas algumas exceçīes, são obsoletos (ou inexistentes) e incompatíveis com as exigências de um curso pré-clínico atual e de razoável qualidade. $\mathrm{O}$ que se discute é a inexistência ou a incompatibilidade de meios com as exigências formadoras do estudante médico.

\section{CORPODOCENTE}

A responsabilidade em ministrar o ensino no ciclo pré-clínico é preocupante e tem conseqüências de grande importância para o futuro da educação médica.

\footnotetext{
- Inquérito naalizado entre ingressantes de esculas mídicas públicas e privadas, no Estadu de São

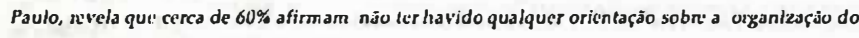
curso. Dados do autor nảo publicados.
}

\footnotetext{
"As the dean of Harvard (Dr. Sidncy Burwell) put it "My students are dismayed whem l say to them, half of what you an tought as medical students will in 10 years have shown to be wrong. And
} the truuble is, none of your teachers knows which half". Pickering, op. cit., p. 115. 
Deve sempre ser lembrado que a construçāo do conhecimento cientifico partiu do empirico para o racional, da observaçāo para a experimentaçāo. Nāo há razāo pedagógica para se consentir que se transmita conhecimento desconectado da motivação que conduziu o aluno até a escola médica."

A diferenciação das ciências pré-clínicas nāo as torna independentes. Elas não podem ser ensinadas apenas como exigência curricular. O professor deve ser capaz de plasmar o espirito do aluno e convencê-lo de que o conteúdo de sua disciplina será de grande valia na formaçāo profissional, embora ele nāo vislumbre àquela etapa a relevância futura da matéria.

É absolutamente inaceitável confiar a formaçāo do aluno a professores nāo-habilitados a promover a integraçāo do conhecimento e seu significado profissional. Alguns professores, ou muitos, podem até mesmo dispor da titulaçāo que os habilita para admissāo no corpo docente do ensino superior; podem, até mesmo, ter desenvolvido trabalho de pesquisa conducente àquela titulaçāo, mas nāo devem ser admitidos quando nāo-habilitados a participar de curso que contempla as necessidades especificas citadas.

Tenha-se presente que se o domínio relativo de parcela de conhecimento de maior ou menor complexidade permitiu-lhe aquela titulaçāo, ela nāo o qualifica como professor de escola médica. A tal respeito, Platt ${ }^{22}$ discute que a disponibilidade de um determinado equipamento torna fácil achar assunto para pesquisa: sempre haverá algo para ser avaliado. É a necessidade para pensar, observar, assimilar, integrar e formular idéias que toma tempo e qualifica.

Estas considerações sāo feitas porque os departamentos básicos estāo, sempre admitindo graduados oriundos dos bacharelados e cursos de pós-graduaçāo em áreas de ciências biológicas e outras, que nāo têm experiência clinica e nem juizo de valor sobre os objetivos da escola médica.

A menos que o biólogro seja pessoa de mente aberta, ele terá como professor, muita dificuldade para modificar o seu ensino que deve atender às necessidades do futuro médico. Por exemplo, o biólogo admitido no departamento de Anatomia, com base em sua experiência de pesquisa em microscopia eletrônica, poderá ter mal desempenho quando chamado para discutir a anatomia do canal inguinal com estudantes, cujo interesse futuro no assunto relaciona-se principalmente com a hérnia inguinal.

O que se discute aqui nāo é novidade mas está se agravando. $O$ problema nāo é só de natureza vocacional; é ta mbém econômico. Nāo há menos recrutas oriundos somente dos cursos médicos (o argumento do baixo salário tem sido enfatizado), como há um excesso de candidatos cujas origens são os bacharelados e programas de pós-graduação em ciências biológicas e outras (em busca de oportunidades de emprego no mercado de trabalho que oferece menor remuneraçāo).

Estes cientistas "puros", que hoje ocupam grande espaço, geralmente nāo sāo capazes de trabalhar em colaboração com os clinicos no ensino, nāo participam dos compromissos e nem das preocupaçōes da educaçāo médica.

O preocupante cenário para os destinos da educaçāo médica, reclama correçāo de rumos; como exemplo, temos a modificaçāo da estrutura curricular discutida por Lent. ${ }^{16}$ Ao invés de continuar ministrando disciplinas isoladas, a mudança postula que o ensino se desenvolva a partir de disciplinas integradas do ciclo pré-clinico com as dos departamentos de aplicaçāo.

Embora sob o aspecto teórico, a idéia de integração pareça muito interessante, uma vez que fornece ao aluno um conhecimento mais harmonioso do organismo, na prática as dificuldades se acumulam. A autonomia desfrutada pelos departamentos ao propor seus programas de ensino-aprendizagem é uma das causas, ${ }^{10}$ agravada pelo grau de liberdade (autoconferida) das disciplinas. ${ }^{3}$

Há, no entanto, outras razōes exploradas ao absurdo, onde os autores ilustram conflitos nascidos de conceitos, competências, desconfianças e metodologias de trabalho.*

Miller, ${ }^{1 y}$ já expressou sérias dúvidas acerca da racionalidade e viabilidade do ciclo pré-clinico da educaçāo médica. Qualquer dire-

\footnotetext{
- If the plan calls for a series of physiological lecturs to be given in the time alloted to the department of obstetrics and gynaccology, and if the head of this department considers the physiologist concerned to be a charlatan, then these lectuns will someduw not to be given after the first yesr. Sinclair, op. cit., p. 54-55.
} 
tor de escola de Medicina, diz ele, que tentar integrar o currículo e prevenir a lacuna iatrogênica entre a etapa pré-clinica e o estágio clínico, onde o conhecimento científico é usado para o benefício do doente, sabe que o principal obstáculo reside nos professores do ciclo "dito" básico. Por exemplo, o puro morfologista e o biólogo fisiologista que gravitam em faculdades, terão dificuldade na transmissão de conhecimentos relevantes no curso médico, mesmo em colaboração com médicos. Conforme Miller destacou, problemas de recrutamento afetam mais o ensino do que as mudanças introduzidas no planejamento acadêmico das instituiçōes.

\section{FASES DE TRANSIÇÃO}

Cabe, aqui, falar de duas transições. Uma relativa à chamada transiçāo paradigmática; a outra, não excludente, diz. respeito à transiçāo da etapa pré-clínica para a fase clínica.

Comecemos pela segunda.

A transição do ciclo científico do curso médico para o ciclo de aplicação é verdadeiramente difícil e não pode ser feita de modo satisfatório, a menos que certos padrōes sejam adotados. Estudantes acham árdua essa fase de transição, por razōes de ordem pedagógica e de natureza psicológica.

É inescapável a discussão da participação da coordenação do curso, do professor, do aluno, do conteúdo programático e dos métodos empregados no ensino. De fato não há coordenação interdepartamental, no ciclo pré-clínico, com a participação de docentes na etapa de aplicação. ${ }^{2.3}$

As carências de ordem pedagógica são comuns e ostensivas. A transição será muito melhor aproveitada se a Fisiologia humana, por exemplo, constituir a ponte entre as duas etapas: as aplicaçōes de Fisiologia aos problemas da doença humana impressionam o aluno tão logo ele adentra o hospital.

No que concerne aos métodos, por exemplo, a não-realização sistemática de necrópsias causa grave prejuízo à formação do aluno, além da perda de um dos meios mais eficientes de avaliar a qualidade dos serviços profissionais prestados.
Cita-se, por oportuna, a observação de Verbicaro: ${ }^{28}$ fator positivo nas aulas-seminários é o fato de o aluno vir conhecendo o assunto, o que torna mais agradável para o professor elucidar apenas as dúvidas. (O destaque é meu: a relevância reside na pressuposição da competência do professor para esclarecer as dúvidas dos alunos. Há vários exemplos: um deles é a incapacidade que tem o professor para comentar situação específica (miocardite) quando a exposição teórica versa sobre inflamação.)

Se nunca é demais sublinhar a importância das disciplinas do ciclo pré-clínico, na fase de transição, também não se pode deixar de lado a observação corrente do esquecimento, pelos alunos, de conceitos básicos ministrados nessas disciplinas. Tal fato leva à necessidade de recordar estes conceitos e conhecimentos na fase de transição do curso. Não se trata de simples caráter de reforço, mas de verdadeiro re-ensinar. ${ }^{13}$

Ao discutir o fenômeno retençāo do conhecimento, Lobo ${ }^{17}$ enfatiza que o esquecimento é devido sobretudo a três fatores: uso, relevância e interferência. Desta forma, um conhecimento tende a ser esquecido se nāo for usado, se não for relevante para o aluno ou se sofrer interferência do aprendizado de outros conhecimentos de maior relevância.*

Estes fatores concorrem para que se admita que a organização do curso médico em ciclos nāo seja pedagógica, nem psicológica, pois além de outros argumentos, não é motivante para o aluno separar o saber do fazer.

Ao analisar a implementação do ciclo pré-clínico, Lent ${ }^{16}$ deixa claro que o primeiro passo na assessoria pedagógica é levar o professor a pensar sobre as funçōes do profissional que ele ajuda a formar. Esta reflexão é importante, pois serve de ponto de partida para uma definição de objetivos que o aluno precisa alcançar para exercer bem sua atividade futura.

Retornemos à fase de transição paradigmática.

Além de apontar os defeitos de muitas escolas, Flexner fez. um exame completo dos pontos essenciais de um bom ensino, acentuando a importância do espírito científico e o grande valor da pesquisa para manter as escolas vivas e promover o progresso da Medicina. ${ }^{* *}$
-Inqućritu realizado entre alunas que concluiram o primeiro ano do ciclo clinico, em cscolas públicase privadas, no Estado de São Paulo, revela que cerce de setenta por cetılu declaram percépşāo de intençāo em se promover "ponte" cntre os tnsinos do ciclo básico e as da primuira utapa cltnica. Essice sesultado significativo, podendo servir de subsidio J cons ti tuiç̧o de "módulu" interdisciplinar na tra nsił̧ào dos dois cicles.
"The differentiation of the pre-clinical sciencus did not at once result in independence on their part( ). The schools lacked the mency and they lacked the interest necessary toscientific development of the pre-clinical sciences () The investigator - even the clinical investigator - is constantly driven back upon then. Flernec, op. cit. p. 27-28, 87. 
Convém notar, da mesma forma, que Flexner discutiu que of funcionamento da escola médica é autorizado pelo Estado, com fundamento na natureza social dos seus serviços. Ela nāo pode, portanto, escapar à crítica e à regulamentação social.

A demanda social levou a escola médica a buscar novas alterna. tivas de atendimento médico e, em conseqüência, de um novo modelo. Mas, em qualquer um desses, é indispensável alcançar algum grau de acordo com um mecanismo que permita definir requisitos mínimos relativos a pessual, instalaçôes e recursos financeiros. ${ }^{8}$

Durante a fase de transição paradigmática nāo se pode deixar de cuidar dessas exigências. Enquanto convivem, por algum tempo, o velho e o novo paradigma não podem escapar à crítica: a escola médica no Brasil em sua esmagadora maioria nāo seguiu os preceitos do paradigma Flexneriano. O que se viu acontecer foi a banalização do ciclo pré-clínico por razōes estranhas às premissas e conceitos que o embasam.

Esta é a liçāo de como velhos símbolos sucumbem às novas necessidades. Porém há outra liçāo: nenhum novo modelo cumprirá adequadamente sua missāo, se nāo houver apreensāo de atitudes, conhecimentos e meios essenciais para o seu desenvolvimento.

Há argumentos suficientes para se repensar, com urgência, o ciclo pré-clínico do curso médico, cujos problemas foram agravados pela forte expansāo do ensino superior, proliferaçāo de escolas médicas e separação dos departamentos pré-clínicos e clinicos. E ao repensar o ciclo pré-clínico, deve-se admitir que o mesmo deverá ter um caráter formativo, a par de sua missāo informativa. ${ }^{17}$

\section{DIÁLOGO}

Conversaçāo vivenciada por um ilustre professor, durante visita de inspeção a uma escola médica paulista.

- "Gostaria de visitar a Fisiologia.

-Lamento nāo ser possível, professol: A Fisiologia só vem às quintas-feiras."

\section{SUMMARY}

The: preclinical teaching, as an educational kevel, is being adversely affiected by the absence of a philosophy which emphasizcs basic sciences as fundarnental knowledge for the fulfillment of qualified academic and profcssional missions. The discussion might contribute to create an agenda for changes - goals and strategy iniciatives.

\section{KEY WORDS}

Medical Education; Basic Sciences; Paradigma.

\section{REFERÊNCIAS BIBLIOGRÁFICAS}

1. AMORIM, D. S. Medicina interna e especialidades não cirúrgicas In: BRASIL. Secretaria do Planejamento. Conselho Nacional de Desenvolvimento Científico e Tecnológico. Avaliaçāo \& Perspectiva, 6, Brasília, 521 p. 1982 . p. 243-350.

2. AMORIM, D.S. Óbice à reorganizaçāo curricular: o departamento. R. Bras. Educ. Méd., Rio de Janeiro, v. 17, n. 2, p. 40, 1993.

3. AMORIM, D.S. The Archaic organization of higher education institutions and its effect on the curriculum. R. Bras. Educ. Méd., Rio de Janeiro, v.19, n. 3, p.12-15, 1995.

4. BECHER, R. Academic tribes and territories: intelectual enquiry and the cultures of disciplines. Bristol: The Society for Research into Higher Education and Open University Press., 1990, p. 20-35.

5. BLOCK, S.R. A Students'view. In: POPPER, H. (ed). Trends in New Medical Schoals. New York: Grune \& Stratton, 1967. p. 129-133.

6. BLOOM,A. O Declínio da Cultura Ocidental: da crise da Universidade à crise da Sociedade. In: AS DISCIPLINAS. Sāo Paulo: Best Seller, 1987. p. 363-397

7. CHAVES, M., ROSA, A. R. (org.) Educação médica nas Américas: o desafio dos anos 90. Sāo Paulo: Cortez Editora, , 1990. 209 p.

8. CHAVES, M.M. Educação das profissões de saúde: perspectivas para o século XXI. R. Bras. Educ. Méd., Rio de Janeiro, v. 20, n. 1, p. $21-27,1996$ 
9. ENSINO médico: bases e diretrizes para sua reformulaçāo. R. Bras. Educ. Méd., Rio de Janeiro, v. 10, n. 2, p. 67-76, maio/ago., 1986. (foi citada em BRASIL. Ministério da Educaçāo. Secretaria de Especialistas do Ensino Médico. Comissāo de Ensino Médico. Ensino. (Documento, 6).

10. FIGUEIREDO, J. F. RODRIGUES, C. R. C. Estratégias para a reformulação da estrutura curricular na Faculdade de Medicina de Ribeirāo Preto na última década e estágio atual do processo. R. Bras. Educ. Méd., Rio de Janeiro, v. 14, n. 1, p. 20-23, 1990.

11. FLEXNER, A. Medical education in the United States and Canada: a report to the Carnegie Foundation for the advancement of teaching. Bulletin Number Four, New York, 1910.

12. HOSSNE, W.S. Responsabilidade ética da linguagem médico-científica. R. Bras. Educ. Méd., Rio de Janeiro, v. 14, v. 1, p. 5-10, 1990.

13. JANSEN, J. M., BEVILACQUA, F., BENSOUSSAN, E. Evasāo do conhecimento nos primeiros anos do curso médico. R. Bras. Educ. Méd., Rio de Janeiro, v. 9, n. 3, p. 170-171, 1985.

14. KUHN, T.S. A Estrutura das revoluçōes cientificas. Sảo Paulo: Perspectiva, 1996.

15. LARSON, K.S. The Dissemination of false data through inadequate citation. J. Int. Med., v. 238, p. 445-450, 1995.

16. LENT, M. A. S. Ensino integrado no ciclo básico. R. Bras. Educ. Méd., Rio de Janeiro, v. 6, n. 2, p.81-88, 1982.

17. LOBO, L. C. G. Ensino das matérias básicas. R. Bras. Educ. Méd., Rio de Janeiro, v. 5, n. 2, p.83-130, 1981.

18. LOPES PONTES, J. P. Ensino médico no Brasil: evolução, perspectivas e desafios. R. Bras. Educ. Méd., Rio de Janeiro, v 6, n. 2, p. 104-110, 1982.

19. MILLER, H. Medical education and medical research. Lancet, v. i, p. 1-6, 1971.

20. PEREIRA, G. O Ensino médico no Brasil. R. Bras. Educ. Méd., Rio de Janeiro, v. 9, n. 3, p.182-186, 1985.
21. PICKERING, G. W. The Purpose of medical education. Br. Med. J., v. 2, p.113-116, 1956.

22. PLATT, R. Medical science: master or servant? Br. Med. J., v. 4, p. 439-444, 1967.

23. ROSA, A.R. Inter-relaçōes dos ciclos básico e profissional. R. Bras. Educ. Méd., Rio de Janeiro, v. 3, n. 3, p.49-53, 1979.

24. SANTOS,J. O. Filosofia da educaçāomédica: interpretaçāo da praxis. R. Bras. Educ. Méd., Rio de Janeiro, v. 10, n. 2, p.82-86, 1986.

25. SINCLAIR, D. Basic Medical Education. London: Oxford University Press, 1972.

26. STOKES, J. F. Examining in the United States the National Board of Examiners. Br. J. Med. Educ., v. 1, p. 320-29, 1967.

27. Van VUGT, F. A., WESTERHEIDJEN, D. E. Towards a general model of quality assessment in higher education. Higher Education, v. 28, n. 3, p.355-371, 1994.

28. VERBICARO, M. G. L. Comparaçāo de métodos de ensino em curso de anatomia patológica. R. Bras. Educ. Méd., Rio de Janeiro, v. 8, n. 3, p.193-196, 1984.

29. WAMMACHER, C. Extinção do ciclo básico. ln: XXXIII CONGRESSO BRASILEIRO DE EDUCAÇĀO MÉDICA, 1995, Porto Alegre. Anais ...Porto Alegre: ABEM, 1995. 304 p. p.167-169.

\section{Endereço do Autor}

Rua Bernardino de Campos, 1236 apt $^{\circledR} 132$

14015-130 - Ribeirão Preto - SP 